\title{
Natural Fractures Characteristics of the Carboniferous Volcanic Reservoir in Northwestern Margin of Junggar Basin
}

\author{
Bei $\mathrm{LV}^{\mathrm{a}}$, Luo YAO ${ }^{\mathrm{a}}$, Bo WANG ${ }^{\mathrm{a}}$, Jian $\mathrm{WANG}^{\mathrm{a}}$ and Lizhi WANG ${ }^{\mathrm{b}, 1}$ \\ a Engineering Technology Research Institute of Xinjiang Oilfield Company, Karamay \\ 834000, China \\ b Petroleum Engineering School, Southwest Petroleum University, Chengdu, Sichuan \\ 610500, China
}

\begin{abstract}
Research on the regional fracture's development is important for reservoir fracturing. This paper takes the Carboniferous volcanic reservoir in the northwestern margin of Junggar Basin as the research object. Based on understanding the regional tectonic faults and geological characteristics, the parameter characteristics of natural fractures are analyzed using imaging logging data, and natural fractures distribution characteristics are compared with regional faults and in-situ stresses, as well as the pattern of natural fractures formation is revealed. The results indicated that: (1) The Carboniferous in the northwestern margin of Junggar Basin area mainly develops $3 \mathrm{NE}$-trending reverse faults. The reservoir type is pore-fracture dual media type, with an average porosity of $7.64 \%$ and an average permeability of $1.16 \mathrm{mD}$, which belongs to the medium-porosity and ultra-low permeability reservoir; (2) Reservoir fractures are generally well developed. High-conductivity fractures and high-resistance fractures coexist, but high-conductivity fractures are the main ones. The fracture width is between 0.053 and $0.23 \mathrm{~mm}$, and the fracture density is between 0.5 and $1.68 \mathrm{strips} / \mathrm{m}$. The length is between $0.54-1.88 \mathrm{~m}$, the fracture porosity is between $3.4 \times 10^{-5}-41 \times 10^{-5}$, and the dominant fracture trend is mainly $\mathrm{NE} 50^{\circ}-\mathrm{NE} 80^{\circ}$; (3) The direction of the maximum horizontal in-situ stress of the reservoir is mainly $\mathrm{NE} 30^{\circ}-\mathrm{NE} 60^{\circ}$, in the direction of $\mathrm{NEE}$, it differs from fracture strike by $10^{\circ}-50^{\circ}$, and roughly the same as the strike of the three reverse faults.
\end{abstract}

Keywords. Petroleum geology, Carboniferous, volcanic reservoir, natural fractures, imaging logging

\section{Introduction}

The sealing and shielding of the up-dip unconformity faults formed in the fractured zone plays a crucial role in the formation lithology and the accumulation of oil and gas reservoirs [1-4]. The complexity of the hydraulic fracture network depends on the cross behavior of hydraulic fractures and natural fractures [5]. Moreover, in the hydraulic fracturing design of unconventional fractured reservoirs, natural fractures, bedding and other discontinuous interfaces are also the main factors which highly affect hydraulic

\footnotetext{
${ }^{1}$ Corresponding Author, Lizhi WANG, Petroleum Engineering School, Southwest Petroleum University, Chengdu, Sichuan 610500, China, Email: wanglizhi_swpu@163.com
} 
fracture propagation [6]. Therefore, the research on the regional fracture development is important for reservoir fracturing.

Regional fractures have close relationships with tectonic faults and in-situ stress [7]. The mechanical behavior of natural fractures under the current stress field state has gradually been recognized as an important factor affecting productivity [8]. Under the action of different periods of stress field, a natural fracture network with specific geometric occurrences and spatial extensions is formed [9], resulting in the formation of faults and the development of complex natural fractures on the two plates of faults. There are a large number of normal faults in the continental rift basin, and the hanging wall of the fault is beneficial to oil and gas drainage, while footwall is beneficial to oil and gas accumulation, especially fault block oil and gas reservoirs with reverse shielding are most developed [10]. The initiation and propagation of fractures in the formation are mainly restricted by local stress fields, types of rock and natural fractures [11]. Tectonic fractures are the most significant storage space of shale reservoirs and can remarkably improve the permeability of the reservoir.

Although some achievements have been made in the study of fracture and fault distribution characteristics in tectonically stressed strata, the historical evolution of stratigraphic structures and in-situ stresses in different regions is very different from the current distribution. There are still few reports on the distribution of fractures in the Carboniferous volcanic reservoir in the northwestern margin of Junggar Basin. Therefore, based on imaging logging technology and interpretation methods, research on the development of fractures in the Carboniferous volcanic reservoir in the northwestern margin of Junggar Basin. and their correlation with tectonic faults and in-situ stress has important theoretical and practical significance for judging reservoir resources and reserves and formulating reservoir fracturing reconstruction measures.

\section{Geological Characteristics of the Work Area}

The northwestern marginal area mainly develops three inverse faults, namely the Beihei Youshan fault, the Karamay No. 1 fault and the Karamay No. 2 fault. The Karamay No. 2 fault and the Beihei Youshan fault are the main faults, the Karamay No. 1 fault is a secondary fault, and the Beihei Youshan fault is The Karamay No. 1 and No. 2 faults not only provide passages for oil and gas migration in this area, but also control the accumulation of oil and gas into reservoirs.

The main lithologies of the Carboniferous volcanic reservoir in the northwestern margin are: volcanic breccia and lava breccia in eruptive facies, basalt and altered basalt in overflow facies, both of which contain oil. Through the study of favorable lithofacies characterization, the deep Carboniferous has developed lower eruptive facies, middle overflow facies and upper eruptive facies rock bodies, which are superimposed and distributed on the profile, and volcanic breccia and basalt appear alternately.

The Carboniferous reservoir is a pore-fracture dual media type, with primary pores, secondary dissolution pores and fractures developed in the storage space. Primary pores are often distributed in an isolated and disordered manner, with poor connectivity and serious filling. However, because tectonic fractures or shrinkage cracks sometimes cut through the pores, the isolated pores are connected to each other and become effective pores. The secondary dissolution pores are generally in the form of small sieve holes with a certain degree of connectivity. In addition, various fractures are developed, which can play a key role in improving the seepage conditions of volcanic reservoirs. The 
porosity of the reservoir is $0.73 \%-34.79 \%$, with an average of $7.64 \%$, and the permeability is $0.01 \mathrm{mD}-8754.00 \mathrm{mD}$, with an average of $1.16 \mathrm{mD}$. It belongs to middle porosity and ultra-low permeability reservoir.

\section{Natural Fracture Identification and Characteristic Parameter Evaluation}

According to the above-mentioned natural fracture identification and characteristic parameter calculation and evaluation methods, the oil producing interval of $1380-1392 \mathrm{~m}$, 1717-1729m of Well J112 and 1279-1291m, 1475-1487m of Well J113 in the study area are analyzed. Highly conductive open fractures appear as dark (black) sinusoidal curves and irregular shapes on the FMI image (due to drilling mud invasion or filling fractures with high conductive minerals). The wellbore is obliquely crossed with an inclination angle of less than $90^{\circ}$, and the shape is sinusoidal. Table 1 shows the fracture data of imaging logging analysis recommended for oil testing in Carboniferous formations in Wells Jin112 and J113.

Table 1. Characteristic parameters of natural fracture imaging logging interpretation.

\begin{tabular}{|c|c|c|c|c|c|c|}
\hline $\begin{array}{l}\text { Well } \\
\text { number }\end{array}$ & $\begin{array}{l}\text { Depth } \\
\text { (m) }\end{array}$ & Fracture type & $\begin{array}{l}\text { Width of } \\
\text { fracture }(\mathbf{m m})\end{array}$ & $\begin{array}{l}\text { Density of } \\
\text { fracture (strips/m) }\end{array}$ & $\begin{array}{l}\text { Length of } \\
\text { fractures (m) }\end{array}$ & $\begin{array}{l}\text { Fracture } \\
\text { porosity }\end{array}$ \\
\hline \multirow{3}{*}{$\mathrm{J} 112$} & $\begin{array}{l}1717- \\
1729\end{array}$ & $\begin{array}{l}\text { High-conductive } \\
\text { fracture }\end{array}$ & 0.23 & 1.68 & 1.88 & 0.00041 \\
\hline & \multirow{2}{*}{$\begin{array}{l}1380- \\
1392\end{array}$} & $\begin{array}{l}\text { High-conductive } \\
\text { fracture }\end{array}$ & 0.1 & 0.58 & 0.78 & 0.00005 \\
\hline & & $\begin{array}{l}\text { High-conductive } \\
\text { fracture }\end{array}$ & 0.17 & 1.12 & 1.46 & 0.000196 \\
\hline \multirow{3}{*}{$\mathrm{J} 113$} & $\begin{array}{l}1475- \\
1487\end{array}$ & $\begin{array}{l}\text { High-conductive } \\
\text { fracture }\end{array}$ & 0.062 & 0.63 & 1.1 & 0.00006 \\
\hline & \multirow{2}{*}{$\begin{array}{l}1279- \\
1291\end{array}$} & $\begin{array}{l}\text { High-conductive } \\
\text { fracture }\end{array}$ & 0.064 & 0.96 & 1.38 & 0.00009 \\
\hline & & $\begin{array}{l}\text { High-conductive } \\
\text { fracture }\end{array}$ & 0.053 & 0.5 & 0.54 & 0.000034 \\
\hline
\end{tabular}

A total of 44 obvious natural open fractures were picked up from the imaging map of the 1380-1392 m well section of Well J112, including 29 high-conductivity fractures and 15 high-resistance fractures. The inclination, tendency and strike distribution of fractures are shown in figure 1. You can see this in table 1 and figure 1 that the fracture width of the high-conductivity fracture in the $1380-1392 \mathrm{~m}$ section is $0.1 \mathrm{~mm}$, the density is $0.58 / \mathrm{m}$, the fracture length is $0.78 / \mathrm{m}$, and the porosity of fracture is 0.00005 . The fracture strike is $5^{\circ}-176.5^{\circ}$, and the dominant strike is $70^{\circ}-100^{\circ}$, which is approximately east-west; the fracture tendency is $95^{\circ}-266.5^{\circ}$, and the dominant tendency is $160^{\circ}-190^{\circ}$, which is approximately north-south; $9.9^{\circ}-75.9^{\circ}$, the dominant inclination is $20^{\circ}-24^{\circ}$. The width of the high-resistance fractures in the $1380-1392 \mathrm{~m}$ well section is $0.17 \mathrm{~mm}$, the fracture density is $1.12 / \mathrm{m}$, the fracture length is $1.46 / \mathrm{m}$, and the porosity of fracture is 0.000196. The fracture strike is $18^{\circ}-176^{\circ}$, the dominant strike is $70^{\circ}-100^{\circ}$, which is approximately east-west; the fracture tendency is distributed between $108^{\circ}-266^{\circ}$, and the dominant tendency is $160^{\circ}-190^{\circ}$, which is approximately north-south; the fracture inclination is distributed from $1^{\circ}$ to $79^{\circ}$, with an average of $38.66^{\circ}$. 


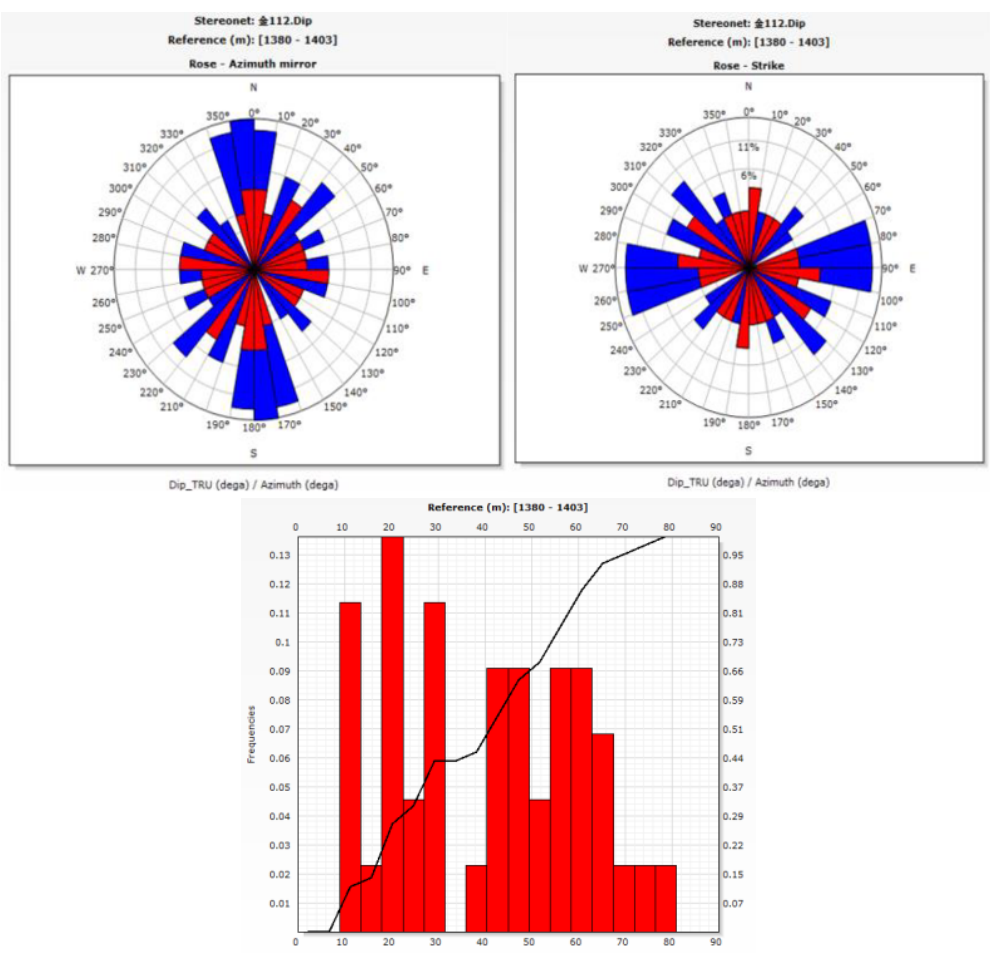

Figure 1. Distribution of fracture inclination, tendency and strike in section 1380-1392m of Well J112: (a) tendency; (b) strike; (c) inclination.

A total of 37 obvious natural open fractures were picked up from the imaging map of the 1717-1729m well in Well J112, all of which are high-conductivity fractures. The distribution map of the inclination, tendency and strike of the fractures is shown in figure 2. It can be seen from table 1 and figure 2 that the average fracture width of the 1717$1729 \mathrm{~m}$ interval is $0.23 \mathrm{~mm}$, the fracture density of the analysis section is $1.68 / \mathrm{m}$, the fracture length is $1.88 / \mathrm{m}$, and the porosity of fracture is 0.00041 . The fracture strikes are distributed in $31^{\circ}-197.4^{\circ}$, and the dominant strike is $60^{\circ}-100^{\circ}$, which is approximately east-west; the fracture tendency is $93.21^{\circ}-269.40^{\circ}$, and the dominant tendency is $150^{\circ}$ $190^{\circ}$, which is approximately north-south; the fracture inclination is $9.2^{\circ}-61.1^{\circ}$, and the dominant inclination is $20^{\circ}-30^{\circ}$. The fracture inclination, tendency and strike are shown in figure 2.

A total of 41 obvious natural open fractures were picked up on the imaging map of the 1279-1291 m well section of Well J113. The inclination, tendency and strike distribution of the fractures are shown in figure 3 . It can be seen from table 1 and figure 3 that the fracture width is $0.062 \mathrm{~mm}$, the fracture density is $0.63 / \mathrm{m}$, the fracture length is $1.1 \mathrm{~m}$, and the fracture porosity is 0.00006 . The fracture strikes are distributed from $1.4^{\circ}-163.5^{\circ}$, and the dominant strike is $50^{\circ}-60^{\circ}$, which is approximately east -eastnorth; the fracture tendency is $91.4^{\circ}$ to $263.5^{\circ}$, and the dominant tendency is $140^{\circ}-150^{\circ}$, which is approximately south-east -south; The inclination is $20.3^{\circ}-79.4^{\circ}$, and the dominant inclination is $20^{\circ}-24^{\circ}, 55^{\circ}-58^{\circ}$. There are 27 high-conductivity fractures in the $1279-1291 \mathrm{~m}$ well section, the fracture width is $0.064 \mathrm{~m}$, the fracture density is $0.96 / \mathrm{m}$, the fracture length is $1.38 \mathrm{~m}$, and the fracture porosity is 0.00009 . The fracture strikes are 
distributed from $27.6^{\circ}-169.4^{\circ}$, and the dominant strike is $40^{\circ}-70^{\circ}$, which is approximately east-east -north; the fracture tendency is from $117.6^{\circ}-259.4^{\circ}$, and the dominant tendency is $130^{\circ}-160^{\circ}$, which is approximately south-east-south; The crack inclination is $21.1^{\circ}-76.9^{\circ}$, and the dominant inclination is $20^{\circ}-24^{\circ}$. There are 14 highresistance fractures in the $1279-1291 \mathrm{~m}$ well section, with fracture width of $0.053 \mathrm{~m}$, fracture density of $0.5 / \mathrm{m}$, fracture length of $0.54 \mathrm{~m}$, and fracture porosity of 0.000034 . The fracture strikes are distributed in $22^{\circ}-98^{\circ}$, and the dominant strikes are $20^{\circ}-40^{\circ}, 80^{\circ}$ $100^{\circ}$, which are approximately east-east-north; the fracture tendency is $110^{\circ}$ to $190^{\circ}$, and the dominant tendency is $110^{\circ}-140^{\circ}$, approximately is in the south-east-south; the fracture inclination is $21^{\circ}-61^{\circ}$, with an average of $30.55^{\circ}$.

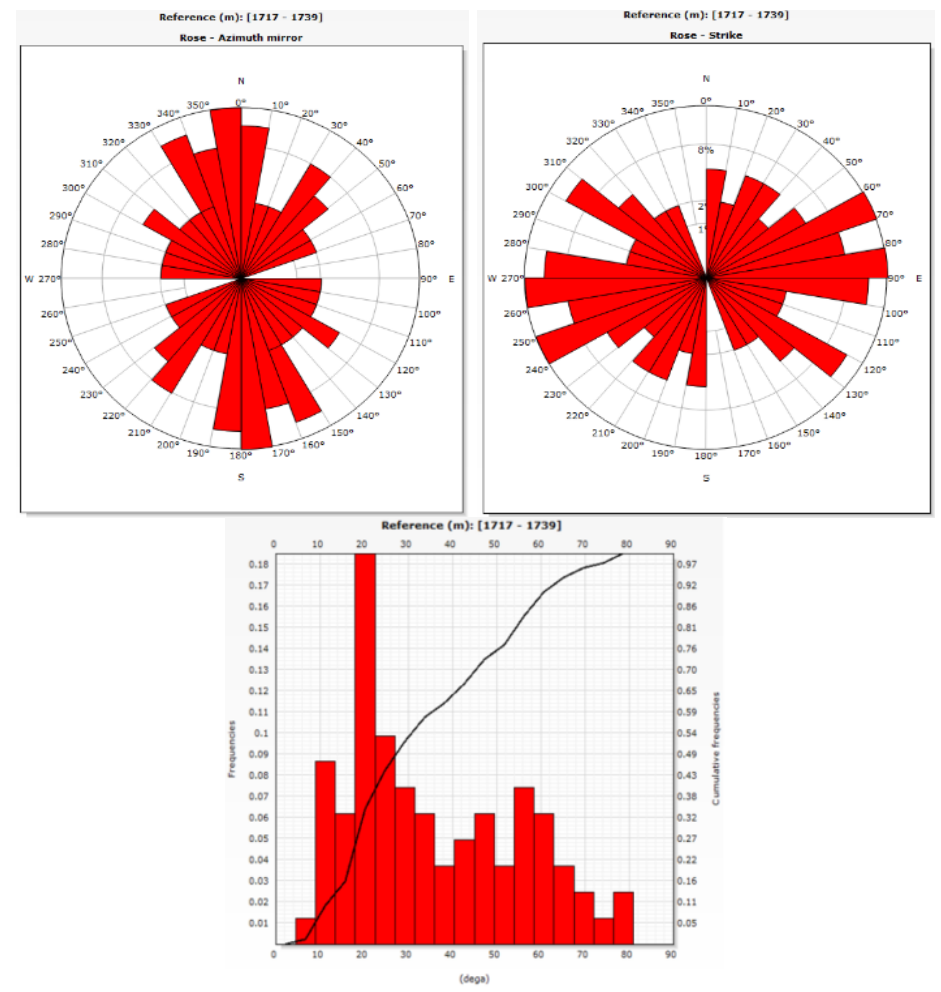

Figure 2. Distribution of fracture inclination, tendency and strike in section 1717-1729m of Well J112: (a) tendency; (b) strike; (c) inclination.

A total of 15 obvious natural open fractures were picked up on the imaging map of the 1475-1487m well section of Well J113, all of which are high-conductivity fractures. The distribution diagram of the inclination, tendency and strike of the fractures is shown in figure 4 . You can see this in table 1 and figure 4 that the average width is $0.062 \mathrm{~mm}$, the crack density is $0.63 / \mathrm{m}$, the average fracture length is $1.1 / \mathrm{m}$, and the porosity of fracture is 0.00006 . The fracture strikes are distributed from $1.4^{\circ}-163.5^{\circ}$, and the dominant strike is $50^{\circ}-60^{\circ}$, which is approximately east-east -north; the fracture tendency is $91.4^{\circ}-263.5^{\circ}$, and the dominant tendency is $140^{\circ}-150^{\circ}$, which is approximately south-east-south; The inclination is $20.3^{\circ}-79.4^{\circ}$, the dominant inclination is $20^{\circ}-24^{\circ}, 55^{\circ}-58^{\circ}$. 


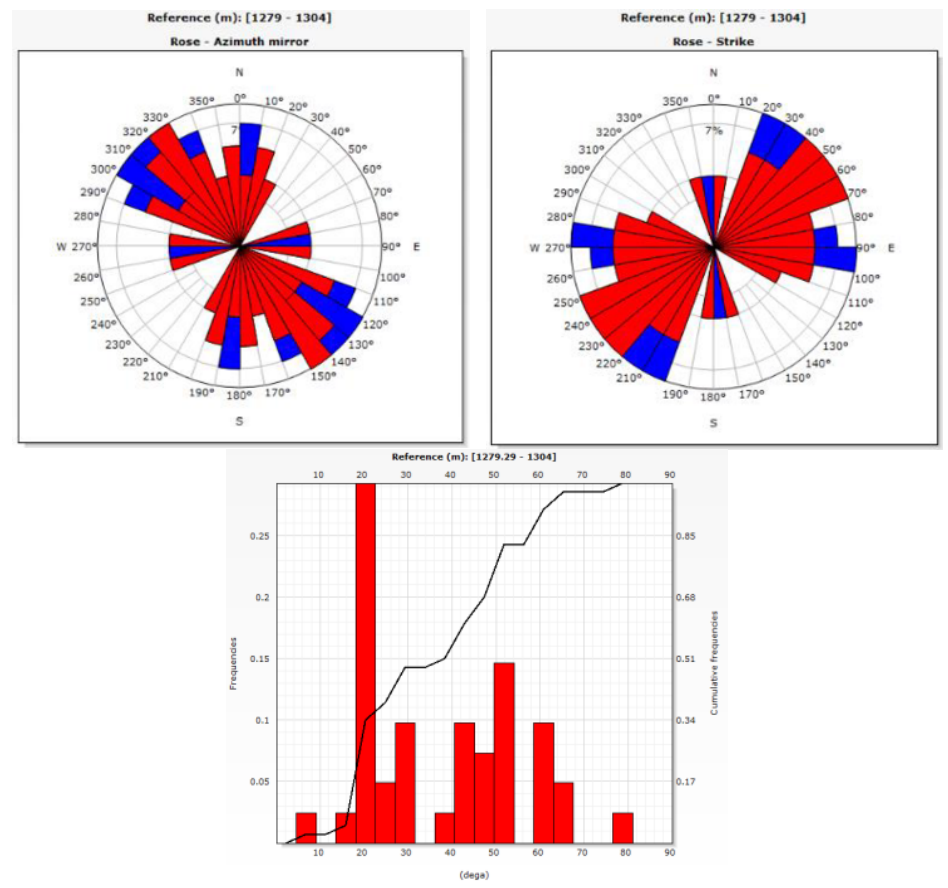

Figure 3. Distribution of fracture inclination, tendency and strike in section 1279-1291m of Well J112: (a) tendency; (b) strike; (c) inclination.

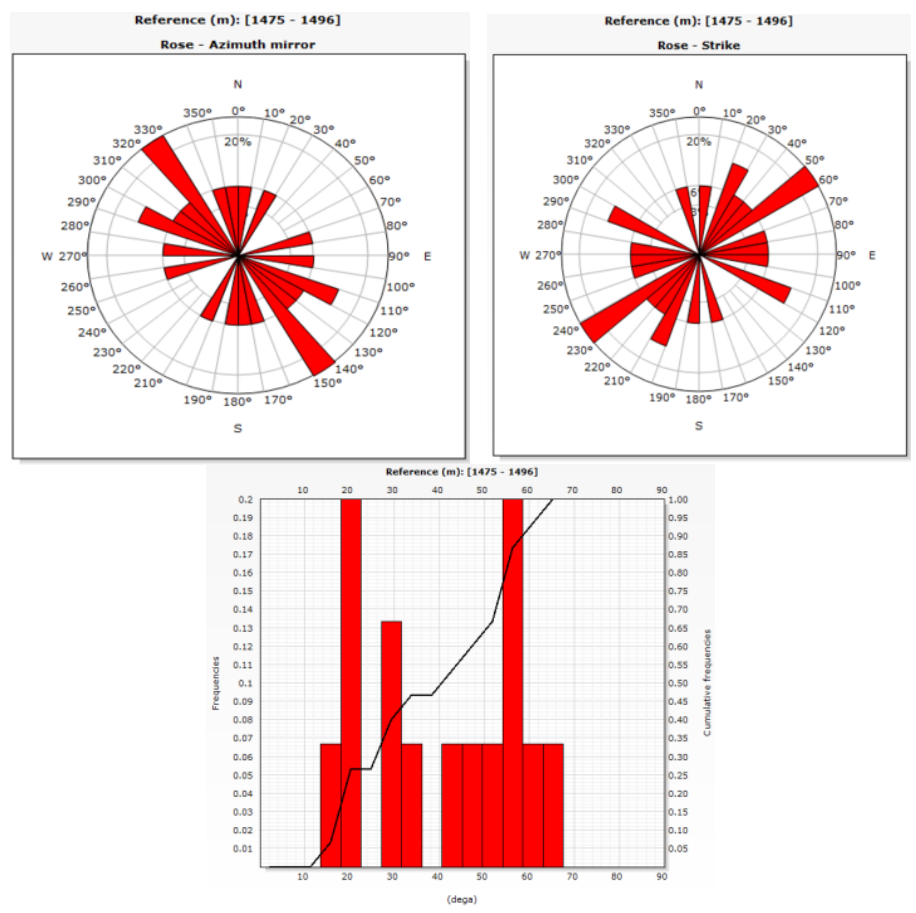

Figure 4. Distribution of fracture inclination, tendency and strike in section 1475-1487m of Well J113: (a) tendency; (b) strike;(c) inclination. 
Summarizing the comprehensive analysis results of the imaging logging data of the two wells, it can be seen that the Carboniferous volcanic reservoir fractures in the northwestern margin of Junggar Basin are generally developed, with high conductivity and high resistance fractures coexisting, but high conductivity fractures are dominant, and the average width of fractures in each layer is $0.053-0.23 \mathrm{~mm}$. The fracture density is between $0.5-1.68$ strips $/ \mathrm{m}$, the length of the fracture is between $0.54-1.88 \mathrm{~m}$, the porosity of the fracture is between $3.4 \times 10^{-5}-4.1 \times 10^{-4}$, and the dominant trend of natural fracture is $\mathrm{NE} 50^{\circ}-\mathrm{NE} 80^{\circ}$ mainly.

\section{Correlation Analysis among Natural Fractures, In-situ Stress Direction and Tectonic Fault}

\subsection{Geological Tectonic Fault Characteristics}

There are Beiheiyoushan, Karamayi No.1 and Karamayi No.2 reverse faults in this area, of which Karamayi No.2 and Beiheiyoushan faults are the main faults and Karamayi No.1 faults are the secondary faults. The fault block of Well 508 is the fault block clamped by the Karamay No. 1 fault and the Karamay No.2 fault.

The top structure of the deep Carboniferous is a wide, gentle nose-like structure with a layer inclination of $1.9^{\circ}-17.9^{\circ}$. Overall, it was higher in the northwest and lower in the southeast, and the highest point was near Well 1903 (table 2).

Table 2. Fracture element table of Carboniferous oil reservoir.

\begin{tabular}{|c|c|c|c|c|c|c|c|}
\hline \multirow[b]{2}{*}{ Title } & \multirow[b]{2}{*}{ Types } & \multirow{2}{*}{$\begin{array}{l}\text { Extension } \\
\text { length }(\mathbf{k m})\end{array}$} & \multirow[b]{2}{*}{$\begin{array}{l}\text { Disconnected } \\
\text { layers }\end{array}$} & \multicolumn{3}{|c|}{ Occurrence } & \multirow{2}{*}{$\begin{array}{l}\text { Fault } \\
\text { displacement } \\
\text { (m) }\end{array}$} \\
\hline & & & & Strike & Tendency & $\begin{array}{l}\text { Inclination } \\
\left({ }^{\circ}\right)\end{array}$ & \\
\hline $\begin{array}{l}\text { Beiheiyoushan } \\
\text { fault }\end{array}$ & $\begin{array}{l}\text { Reverse } \\
\text { fracture }\end{array}$ & 14.8 & $\mathrm{~J}-\mathrm{C}$ & NE-E & NW-N & $5-80$ & $40-90$ \\
\hline $\begin{array}{l}\text { Karamay No. } \\
\text { fault }\end{array}$ & $\begin{array}{l}\text { 1Reverse } \\
\text { fracture }\end{array}$ & 6.0 & $\mathrm{~J}-\mathrm{C}$ & $\mathrm{NE}$ & NW & $5-70$ & $410-690$ \\
\hline $\begin{array}{l}\text { Karamay No. } \\
\text { fault }\end{array}$ & $\begin{array}{l}\text { 2Reverse } \\
\text { fracture }\end{array}$ & 15.6 & $\mathrm{~J}-\mathrm{C}$ & $\mathrm{NE}$ & NW & $5-80$ & $720-1100$ \\
\hline
\end{tabular}

\subsection{Directional Characteristics of In-Situ Stress}

Base on XRMI image data, figure 5 shows the results of in-situ stress analysis by picking up the elliptical borehole and induced fracture of Well J112 in this well area. You can see this in figure 5 that the directions of maximum horizontal in-situ stress obtained by two interpretation methods are consistent well, and the maximum horizontal in-situ stress mainly ranges from $\mathrm{NE} 30^{\circ}$ to $\mathrm{NE} 60^{\circ}$, showing NEE. 


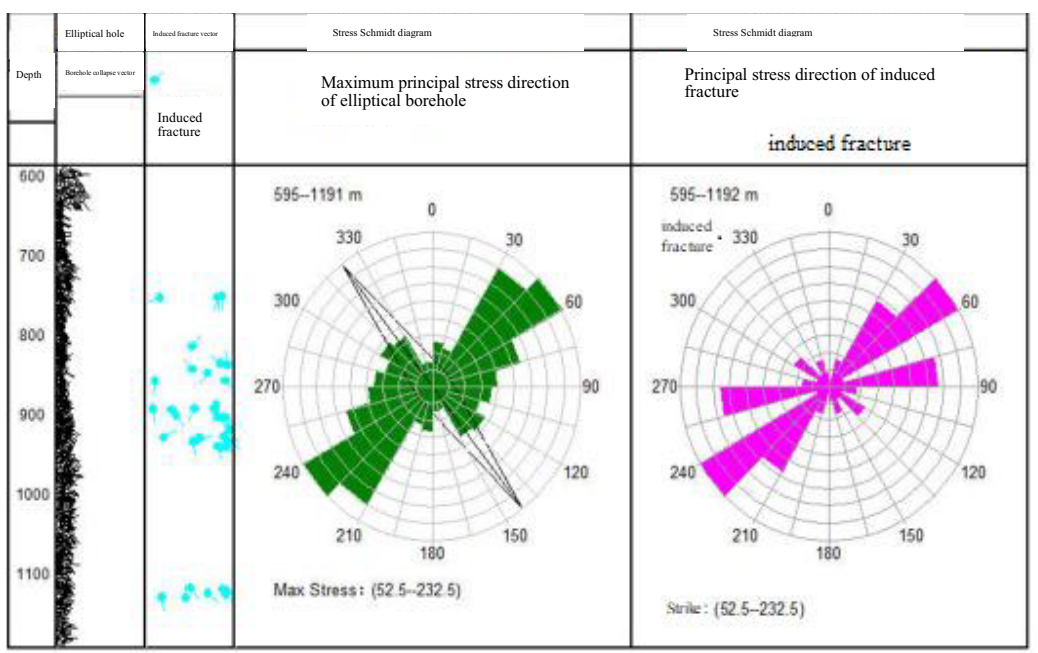

Figure 5. Direction of the maximum horizontal principal stress of the Carboniferous volcanic reservoir in the northwestern margin of Junggar Basin.

\subsection{Correlation Analysis}

The analysis in section 4.1 shows that the Carboniferous volcanic reservoir in the northwestern margin is a reverse fault with a strike of NE, and section 4.2 analysis get the largest horizontal in-situ stress is NEE. Therefore, the stratum tectonic fault is mainly compressed by paleo-in-situ stress to produce a reverse fault, and due to the development of faults, the ancient maximum horizontal in-situ stress direction (NW) was relieved of stress, so that the maximum horizontal in-situ stress direction was deflected and the current maximum horizontal in-situ stress showed the characteristics of NEE. However, natural fractures are affected by both paleo-in-situ stress and current in-situ stress. The ancient tectonic stress field controls the formation, distribution and development of natural fractures. The current in-situ stress not only controls the current underground occurrence and opening and connection of natural fractures formed by the paleo-in-situ stress, but also induces new natural fractures. The tectonic fractures produced by tectonic stress are a group of tensile fractures parallel to the maximum principal stress or two groups of shear fractures perpendicular to each other. The acute bisector of the shear fractures is parallel to the maximum principal stress, and the intersection line of each group of fractures is parallel to the maximum principal stress. Intermediate principal stress. The tectonic fractures produced by tectonic stress are a group of tensile fractures parallel to the maximum principal stress or two groups of shear fractures perpendicular to each other. The acute bisector of the shear fractures is parallel to the maximum principal stress, and the intersection line of each group of fractures is parallel to the intermediate principal stress. The opening condition of the fracture is related to the force in the normal direction of the fracture surface, and the force in the normal direction of the fracture surface depends on the relationship between the natural fracture direction and the stress state of the modern stress field. When the direction of the natural fracture is parallel to the direction of the maximum horizontal principal stress of the modern stress field, the opening of the natural fracture in the ground is the largest, the connectivity is the best, and the fracture has the strongest fluid conductivity. When the natural fracture direction is perpendicular to the maximum horizontal principal stress direction, the 
fracture opening is the smallest, the connectivity is the worst, and the fluid conductivity is the weakest.

By comparative analysis of the maximum horizontal in-situ stress of the Carboniferous volcanic rock strata and the strike of natural fractures in the northwestern margin, it can be seen that the difference between the two directions is $10^{\circ} \sim 50^{\circ}$. The NEtrending reverse fault appears due to the tectonic stress of the formation. The stress release in the direction of the maximum horizontal in-situ stress causes the direction of the maximum horizontal in-situ stress to be deflected to the NEE direction, so that the natural fractures of the formation are simultaneously affected by the paleo-in-situ stress field and the current tectonic stress field, and mainly present shear fractures perpendicular to each other. The in-situ stress will promote the closure of natural fractures formed by the paleo-in-situ stress field, and the current stress field fractures are distributed at an angle lower than $45^{\circ}$ to the NEE direction. This law can better explain the tectonic fault characteristics of the formation, the current maximum horizontal insitu stress direction and the correlation characteristics of natural fracture occurrence.

\section{Conclusion}

(1) The geological characteristics of the work area reveal that the Carboniferous in the northwestern margin mainly develops 3 NE-trending reverse faults. The reservoir type of the Carboniferous is a dual medium type of pore-fracture. The storage space has primary pores, secondary dissolved pores and fractures. The porosity of the reservoir is $0.73 \%-34.79 \%$, with an average of $7.64 \%$, and the permeability is $0.01 \mathrm{mD}-8754.00 \mathrm{mD}$, with an average of $1.16 \mathrm{mD}$. It belongs to middle porosity and ultra-low permeability reservoir.

(2) Fractures in the Carboniferous volcanic reservoir in the northwestern margin of Junggar Basin are generally developed. High conductivity and high resistance fractures coexist, but high conductivity fractures are the main ones. The average width of fractures in each layer is $0.053-0.23 \mathrm{~mm}$, and the fracture density is $0.5-1.68$ strips $/ \mathrm{m}$, the fracture porosity is $3.4 \times 10^{-5}-4.1 \times 10^{-4}$, and the dominant trend of natural fractures is NE50 $0^{\circ}$ $\mathrm{NE} 80^{\circ}$.

(3) The maximum horizontal in-situ stress of the Carboniferous volcanic reservoir in the northwestern margin of Junggar Basin is mainly NE30 $-\mathrm{NE} 60^{\circ}$, which is in the NEE direction, which differs from the natural fracture strike by $10^{\circ}-50^{\circ}$, and is roughly the same as the strike of the three reverse faults.

\section{References}

[1] Fan J M, Qu X F, W C, et al. 2016 Natural fracture distribution and a new method predicting effective fractures in tight oil reservoirs of Ordos Basin, NW China Petroleum Exploration and Development 43 (5) 740-748. (in Chinese)

[2] Zhou X G, Zhang L Y and Fan K 2006 The research situation and progresses of natural fracture for low permeability reservoirs in oil and gas basin Geological Review 52 (6) 777-782. (in Chinese)

[3] Fan J M, Yang Z Q, Li W B, et al. 2015 Assessment of fracturing treatment of horizontal wells using SRV technique for Chang-7 tight oil reservoir in Ordos Basin Journal of China University of Petroleum (Edition of Natural Science) 39 (4) 103-110. (in Chinese)

[4] Zhao J Y, Fan J M, He Y H, et al. 2015 Optimization of horizontal well injection-production parameters for ultra-low permeable tight oil production: a case from Changqing Oilfield, Ordos Basin. Petroleum Exploration and Development 42(1) 68-75. (in Chinese) 
[5] Cheng W, Jin Y, Chen M, Xu T, Zhang Y K and Diao C 2014 A criterion for identifying hydraulic fractures crossing natural fractures in 3D space Petroleum Exploration and Development 41 (3) 336-340. (in Chinese)

[6] Zhang G Q, Zhou D W, Dou J M, Nie Y X and Dong H R 2019 Experiments on hydraulic fracture propagation under action of natural fractures and crustal stress difference Journal of China University of Petroleum 43 (5) 157-162. (in Chinese)

[7] Chen Z M, Zhao D A and Yu Y Y 2011 The interaction mechanism of surrounding rock and supporting structure in high geostress extrusion fault Advanced Materials Research 1269 (243) 3588-3598.

[8] Hennings P, Allwardt P and Paul P 2012 Relationship between fractures, faultzones, stress, and reservoir productivity in the suban gas field, Sumatra, Indonesia AAPG Bulletin 96 (4) 753-772.

[9] Gale J F W, Reed R M and Holder J 2007 Natural fractures in the Barnett shale and their importances for hydraulic fractures treatments AAPG Bulletin 91 603-622.

[10] Peng L, Yang J, Ranjith P G, Zheng Z and Chen J 2016 Experimental investigation of the effects of heterogeneity and geostress difference on the 3D growth and distribution of hydrofracturing cracks in unconventional reservoir rocks Journal of Natural Gas Science and Engineering 35 541-554.

[11] Huang S P, Liu D M, Yao Y B, Gan Q, Cai Y D and Xu L L 2017 Natural fractures initiation and fracture type prediction in coal reservoir under different in-situ stresses during hydraulic fracturing Journal of Natural Gas Science and Engineering 43 69-80. 